\title{
ESTADO ACTUAL DE LA HISTORIA DEL LIBRO EN ESPAÑA
}

François LOPEZ

Universidad de Burdeos 

En un reciente estudio que ha llegado en Francia hasta el gran público, el historiador norteamericano Robert Darnton, de la Universidad de Princeton, caracterizaba del modo siguiente las distintas orientaciones que vienen dando a la historia del libro los especialistas franceses y británicos:

«De manera bastante paradójica, los franceses que se han afanado muy especialmente en sacar la historia del libro del dominio de la pura erudición parecen haberse desinteresado de los procesos de producción y distribución. La investigación francesa tiende a ser estadistica y sociológica. Se plasma generalmente en visiones de conjunto macroscópicas de la producción del libro o en análisis microscópicos de bibliotecas individuales. Los británicos al contrario han prolongado sus encuestas hasta los libros de caja de editores y libreros y no han trabajado tan sólo en los archivos gubernamentales y notariales. Es posible que, asociando el empirismo británico y el interés de los franceses por la historia social en sus grandés líneas, lleguen los americanos a adoptar una concepción original del la historia del libro'(1)n.

No cabe duda que Darnton, al aludir a la investigación francesa sobre la historia del libro que "tiende a ser estadistica y sociológica", pensaba en los trabajos de R. Estivals: Le Dépôt légal sous l'Ancien Régime, de 1537 à 1791, París, 1961; La Statistique bibliographique de la France sous la Monarchie au $X V I I I^{\circ}$ siècle, París, 1965, etc., y en lo relativo a la tendencia sociológica en la obra monumental de H.-J. Martin, Livre, pouvoirs et société à Paris au XVII' siècle, 2 t. Genère, 1969.

En cuanto al empirismo británico, ha sido abundantemente ilustrado, desde los tiempos en que en Gran Bretaña se asentaron las bases de la bibliografía material, por una serie de realizaciones ejemplares entre las que resaltan las de C. Clair, A History of printing in Britain, Cassel, Londres, 1965; H. Plomer, A Dictionary of the printers and booksellers who were at work in England, Scotland and Ireland from 1668 to 1725, Londres, 1922; I. Maxted, The London Book Trades, 1775-1800, Folkestone, 1977. Otros trabajos podrían mencionarse ya que la ciencia británica en este sector ha llegado a un grado de desarrollo ciertamente pasmosol1 bis). 
También Holanda, Bélgica, Suiza y Alemania cuentan con magníficos eștudios en el amplio campo de la historia del libro.

Justo es añadir que, superando el análisis puramente estadístico y sociológico (que, si bien fue dominante en Francia, no llegó a excluir en los últimos veinte años el estudio de la difusión del libro, como lo prueban los excelentes trabajos de R. Chartier, por ejemplo: "Livre et espace: circuits commerciaux et géographie culturelle de la librairie lyonnaise au XVIII sièc/e(2) "), se publicó el año pasado el primer tomo de una Histoire de l'édition française (Le livre conquérant. Du Moyen Âge au milieu du XVI/ ${ }^{\circ}$ siècle, magna empresa dirigida por H.-J. Martin y R. Chartier con la colaboración de J.-P. Vivet, en la que, de las cuestiones de bibliografía material a las áreas de difusión de los textos, de la historia social de las ideas y del gusto a los problemas de la lectura en los distintos ámbitos en que era ésta posible, se intenta realizar una historia total de este singular producto cultural que es el libro.

Pasando ahora a hacer un nuevo balance de las investigaciones sobre el libro en España, de las que han dado lugar a publicaciones y de algunas que permanecen inéditas y cuyos resultados nos han sido participados por sus autores, forzoso nos será decir que, a pesar de notables aportaciones que iremos señalando, las carencias en este sector historiográfico son tanto más graves cuanto que siguen faltando los instrumentos básicos que se necesitan para subsanarlas. Nos referimos sobre todo a las bibliografías. Al tocar este punto, advertía C. Péligry en su artículo «Où en est I'histoire du livre en Espagne?" que en su casi totalidad vienen ya menciọnados los repertorios bibliográficos en el Manuel de l'hispanisant de R. Foulché-Delbosc(3). No ha tenido verdadera continuación la admirable Blbliografia madrileña de C. Pérez Pastor, que, abarcando el período 15661625, fue publicada entre 1891 y 1907 . Sobre los años posteriores (hasta 1631) las noticias recogidas y publicadas por A. Sierra Corella sólo pretenden ser apuntes. Lo cual significa que no sabemos cuál fue la producción tipográfica madrileña de 1625 al final del XIX. Sin computadora, un hombre solo, que además nos dejó las bibliografías de Toledo y Medina del Campo, hizo más que todos los bibliotecarios y archiveros que en lo que va de siglo han tenido altas responsabilidades en la capital de España. 
Barcelona, aunque por fin ha sido publicada la importante contribución de A. Millares Carlo a la historia de la imprenta en dicha ciudad en el siglo XVI, no está en una situación más boyante que Madrid en lo que a los siglos posteriores se refiere. Mucho provecho se puede sacar de las eruditas noticias de J. M. Madurell Marimón sobre el período 1474-1553, así como de su recopilación de "Licencias reales para la impresión y venta de libros (1519-1705)", publicada en la Revista de Archivos, Bibliotecas y Museos (t. LXXII, 1964-1965, p. 111-148). Pero no disponemos de una verdadera bibliografía catalana para el período que va desde la segunda mitad del $X V I$ a fines del XIX.

Tampoco la hay para Valencia. Dejemos aparte la magnífica tesis de Philippe Berger, de la que hablaremos después, y la muy clásica Reseña histórica en forma de diccionario de las imprentas que han existido en Valencia desde la introducción del arte tipográfico en España hasta el año 1868, de Serrano y Morales (Valencia, 1898-1899), que no tiene equivalente en España y fue en su tiempo una de las mejores obras del mundo en su categoria, pero que no permite hacer un estudio cuantitativo de la producción editorial valenciana entre el siglo XVI y el XX. Otra ciudad que fue en Siglo de Oro un importante núcleo editorial, aunque no la podemos comparar con los principales centros europeos, Sevilla, cuenta con varias bibliografías que han ido sucediéndose y complementándose, desde la muy venerable de Escudero y Perosso, premiada por la Biblioteca Nacional en 1864 , pero que no vio la luz hasta treinta años más tarde, hasta las adiciones de Montoto y luego Pérez Gómez. Mucho más recientemente, y ateniéndose a las producciones del siglo XVIII, ha publicado F. Aguilar Piñal un volumen titulado Impresos sevillanos del siglo XVIII (Madrid, C.S.I.C., 1974). Son adiciones a la tipografía hispalense y alcanzan el impresionante número de 2289 noticias (casi tanto como lo recogido por Escudero y. Perosso en su Tipografía, que abarca del siglo XVI hasta finales del XVIII). Si tal es el suplemento que un concienzudo bibliógrafo de hoy puede añadir a las noticias de sus predecesores limitándose a un siglo en que Sevilla ha perdido gran parte de su antiguo esplendor, bien puede suponerse que la bibliografía de los siglos XVI y XVII anda muy falta de ediciones y enmiendas. 
De modo que cualquier estudio cuantitativo y comparativo de los principales centros tipográficos de España en los siglos XVI, y sobre todo XVII, XVIII y XIX es por ahora azaroso y dificultoso, dada la desigualdad de informaciones con que nos encontramos respecto a las ciudades que fueron dotadas de topobibliografías: Sevilla, Medina del Campo, Toledo, como ya va dicho, Alcalá de Henares, Valladolid, Córdoba, Zaragoza, Cádiz, Cuenca, Jerez de la Frontera, Lérida, Orihuela, Segovia, León. La de Burgos está hecha pero queda inédita, y de la de Salamanca se ha publicado tan sólo un avance muy modesto. Salvo error, La Imprenta en Málaga del P. A. Llordén (Málaga, 1973, 2 vol.) es la última topobibliografia sistemática que ha visto la luz. Eoo en cuanto a las ciudades. Pero hay que tener en cuenta también las bibliografias regionales, de Aragón, Extremadura, Galicia, Navarra, La Rioja.

Las lagunas que pone en evidencia este panorama son enormes. $Y$ es que hay que acordarse de que en un pais que fue la patria de un León Pinelo y un Nicolás Antonio mucho tardaron en aparecer durante el siglo pasado los boletines y catálogos sistemáticos para uso de los profesionales del libro. La miseria que puede observarse al respecto agiganta la figura de un Dionisio Hidalgo que siempre soñó con dotar a su país de un equivalente de la Bibliographie de la France que venía publicándose con varios títulos desde 1811.

Luego, con muy distinta perspectiva, promovió la Biblioteca Nacional de Madrid una serie de estudios sistemáticos de la producción tipográfica de cada ciudad.

Nacia asi la bibliografía científica moderna española, cuyas realizaciones ya hemos mencionado. Estas monografías, que habria que completar con sucesivas adiciones ya que algunas son realmente muy deficientes y todas, inevitablemente, exigen enmiendas porque las ediciones falsificadas menudearon en España como en otros países y la bibliografia requiere mucho más que copiar un pie de imprenta y describir un impreso, han sido superadas, en cuanto al periodo primitivo de la imprenta española se refiere, por los clásicos trabajos de K. Haebler, F. C. Sainz de Robles y J. F. Norton. Ese periodo antiguo y, de manera más amplia, la época del Renacimiento es el campo de investigación que más ha atraído y sigue atrayendo 
a los eruditos, bibliófilos y bibliógrafos, como bien lo evidencian las valiosas contribuciones de Carlos Romero de Lecea, Antonio Odriozola, Guillermo S. Sosa y Joaquín Salcedo lzu a una Historia de la imprenta hispana de reciente aparición (Madrid, 1982).

No son tan numerosos los investigadores que después de $\mathrm{C}$. Pérez Pastor han trabajado o están trabajando sobre el XVII español. De la monumental Bibliografía de la literatura hispánica de J. Simón Díaz, que siendo, como reza su título, una bibliografía de autores, e incluyendo además una bibliografía sobre dichos autores, está todavía sin publicar más de treinta años después de su comienzo aproximadamente la mitad. Debido a su concepción poco atinada, es muy improbable que aparezca algún dia su último volumen. De mucha más utilidad nos parece ser otro trabajo del mismo autor: Impresos del siglo XVII (Madrid, 1972) en que se describen unas 3.500 ediciones príncipes en lengua castellana.

A las concepciones discutibles de J. Simón Díaz ha tenido que someterse F. Aguilar Piñal en la Biblioteca de autores españoles del siglo XVIII de las que dos tomos han salido ya y el tercero no tardará. Trabajando con proba y plena dedicación en la bibliografía del siglo XVIII, ha proporcionado ya este estudio excelentes instrumentos de trabajo entre los que destacaremos el Romancero popular del siglo XVIII, el repertorio de La Prensa española en el siglo XVIII. Diarios, revistas y pronósticos. Muy atinadamente suele $F$. Aguilar Piñal añadir a sus bibliografías indices topográficos e índices de impresores, lo cual es de gran interés en la perspectiva de una historia de la imprenta en España, que queda todavía por hacer.

Quien quiera lanzarse en esta empresa no tendrá más remedio de momento que echar mano de estudios anticuados y en todo caso muy incompletos.

Incluso para el siglo XVI que, con la época de los incunables es el mejor conocido, son muy insuficientes los repertorios. Millares de relaciones, de pliegos sueltos y de otros impresos de las más diversas categorías están sin catalogar en bibliotecas españolas. El Tesoro bibliográfico español, emprendido y coordenado desde la Biblioteca Nacional de Madrid para la catalogación de todos los impresos (del XV al XVIII) conservados en bibliotecas españolas, no pasa todavía del siglo XVI y los volúmenes 
correspondientes a este periodo no están todos confeccionados. Las fichas fotocopiadas que en dicho Tesoro se reunen no están hechas con uniformidad de criterios, defecto que pude corregirse rápidamente. Huelga decir que la continuación de esta obra es esperada con ansia por toda la comunidad científica nacional e internacional, pero aunque el empleo de la informática acelera y uniforma el acopio de datos, hay tanto que hacer todavía en algunas bibliotecas de ricos fondos casi desconocidos que es muy poco probable que tan fundamental labor pueda llevarse a cabo en un futuro próximo.

Mientras tanto el investigador que no puede estar viajando constantemente de una ciudad a otra, se ve obligado no pocas veces a acudir aún a unos trabajos tan antiguos como el "Ensayo de un catálogo de impresores españoles desde la introducción de la imprenta hasta fines del siglo XVIII" de $M$. Gutiérrez del Caños(4), que deja mucho que desear pero brinda a veces una información que no se encuentra en estudios modernos. El espléndido Manual gráfico, descriptivo del Bibliofilo Hispano-Americano de Vindel es también una mina de informaciones sobre impresores. Pero quien quiera disponer de numerosos datos sobre la producción tipográfica española durante más de cuatro siglos y esbozar ya unos sondeos estadísticos, sólo podrá echar mano del tan conocido Manual del librero hispanoamericano de Palau, cuya reedición está terminada y al cual se añaden ahora unos tomos de apéndices. Es de esperar que la sugerencia de un inteligente bibliografo de que un índice de impresores venga a rematar este monumento se acepte y surta los debidos efectos. Al Manual de Palau le falta probablemente más del $50 \%$ de la producción conservada en bibliotecas españolas y extranjeras. Además cualquiera puede comprobar que menudean los errores. Con esto y todo, teniendo en cuenta que emprendió este trabajo inmenso un hombre solo, justo será decir que una labor de estas proporciones no tiene equivalente en ninguna parte.

\section{HACIA UNA HISTORIA DEL LIBRO EN ESPAÑA}

Si es obvio que no puede haber historia del libro sin bibliografías, sabido es también que, constituyéndose ésta en disciplina autónoma, se sitúa ya, ambiciosamente, en la intersección de otras historias: la política (siendo determinantes las relaciones entre la edición, la administración, los poderes), la económica (es el libro un producto manufacturado durante 
siglos, industrial después, que como cualquier producto está sometido a fluctuaciones económicas regionales, nacionales, internacionales, y a infraestructuras), la social (ya que no es el impreso un producto como los demás, sino algo que capta, hace y conserva cultura, a la par que va destinado a un público, reducido o masivo según la naturaleza del texto y la estrategia editorial adoptada). Asi viene a ser la historia del libro una vía de acceso a esa zona central en que las interacciones de lo económico, lo social, lo político, lo cultural configuran un estado de civilización. En efecto, además de la producción tipográfica propiamente dicha (e imposible de reconstruir en su totalidad por las destrucciones ocurridas), abarca sectores de la historia social, desde la de los indivíduos que escribían los textos hasta la de los maestros, oficiales y aprendices que fabricaban los libros y los vendian en tiendas, "puestos" o "paradas", por calles y mercados, etc., sin olvidar, claro está, a los lectores, los cuales forman la categoría más numerosa y borrosa, más difícil de delimitar por más enseñanzas que se puedan sacar de los inventarios de bibliotecas. Todo lo relativo al "business", que, legitimamente ha atraido hace tiempo la atención de los investigadores anglosajones, puede y debe cmpaginarse con otras indagaciones, por ejemplo con las que señalaba Lucien Febvre, maestro de tantos historiadores franceses, particularmente de H.-J. Martin que es la figura más destacada en este sector y cuyas obras sirven de modelos.

Procurando evitar fastidiosas acumulaciones de referencias bibliográficas, haremos sólo mención de algunos instrumentos de trabajo, en su mayoria recientes, que en nuestra opinión todo investigador en este campo debe tener constantemente a mano. Siguen siendo imprescindibles las obras clásicas de P. Bohigas, El libro español (ensayo histórico), BarceIona, 1962, y de A. Millares Carlo, Introducción a la historia del libro y de las bibliotecas, México, 1971. Los textos legislativos referentes al libro y a la imprenta (licencias, censuras, etc.) pueden ser consultados en las sucesivas ediciones de Recopilaciones oficiales (Nueva, Novísima, etc.), pero es mucho más cómoda la lectura de los Apuntes para una historia de la legislación española sobre imprenta desde el año de 1480 al presente de J. E. de Eguizabal (Madrid, 1879). Ahora bien, no todas las disposiciones se declararon en textos oficiales ni todas las leyes se cumplieron, como to expresa con meridiana claridad la reiteración de reglamentos y prohibi- 
ciones. La práctica, indudablemente, distaba mucho de lo dispuesto por los poderes. Sería muy ingenuo creer que la observancia era la regla y el incumplimiento la excepción. Muy importante también es saber que se tomó alguna vez una medida muy grave de la que no se encuentra el menor rastro en las Recopilaciones. Una orden oral dada al censor del Consejo de Castilla surtió más efectos que varias leyes impresas en letras de molde. Véase al respecto lo revelado por J. Moll en sus artículos: "Diez años sin licencias para imprimir comedias y novelas en los reinos de Castilla: 16251634", Boletín de la Real Academia Española, t. LIV, cuad. CCl.-Enero-Abril 1974, p. 97-103; y "Por qué escribió Lope La Dorotea", Sociedad Española de Literatura General y Comparada, 1616, II (1979). Del mismo autor son tambièn indispensables las consideraciones expuestas en "Problemas bibliográficos del libro del Siglo de Oro", Boletín de la Real Academia Española, 59 (1979), p. 49-107, y en "El libro en el Siglo de Oro", Edad de Oro, Departamento de Literatura Española. Universidad Autonóma de Madrid, 1982, p. 43-54.

Es J. Moll el mejor especialista de bibliografía material que hay en España, y este ramo de nuestros estudios, que nació y alcanzó un extraordinario nivel de tecnicidad en Inglaterra y Estados Unidos, está considerado también en Francia ahora como una de las disciplinas que deben integrar la historia del libro. Es de desear que J. Moll forme escuela y que se enseñe la bibliografía material en varias universidades de España. ¿Cómo ha de ser posible, de otro modo, hacer estudios cuantitativos, estadisticos y comparativos de la producción de los principales centros tipográficos españoles si nadie sabe reconocer las ediciones falsificadas que fueron tan numerosas antaño?.

Sobre la imprenta y la librería españolas del Siglo de Oro son de gran valia los trabajos publicados por $C$. Péligry que ha adoptado los métodos de H.-J. Martin. Hace años que ha emprendido este investigador una tesis sobre impresores y libreros madrileños en la época de los Habsburgos, y entre sus publicaciones cabe destacar «El inventario de Sebastián de Robles, librero madrileño del siglo XVIl", Madrid, Cuadernos bibliográficos, vol. 32, 1975, p. 1-18; “El Monasterio de San Lorenzo de El Escorial y la difusión de los libros litúrgicos en España (1573-1615)», Primeras jornadas de bibliografía, Madrid, Fundación Universitaria Española, 1977, p. 465-473; 
"Un libraire madrilène du Siècle d'Or. Francisco Lopez le Jeune (1545-1608)", Mélanges de la Casa de Velázquez, t. XII (1976), p. 219-250; "Les difficultés de l'édition castillane au XVII ${ }^{\circ}$ siècle á travers un document de l'époque", Mélanges..., t. XIII (1977), p. 257-284; "La Oficina Plantiniana, el Monasterio de El Escorial y los libros litúrgicos en España durante el siglo XVII", Madrid, Cuadernos bibliográficos, vol. 37, 1978, p. 1-18.

Importantes adiciones a los datos sin elaborar que dejara C. Pérez Pastor son los documentos publicados por M. Agulló y Cobo en los Anales del Instituto de Estudios Madrileños (t. I, (1966), p. 169-208; t. II (1967), p: 175-213; t. III (1968), p. 81-116; t. VIII (1972), p. 159-192; t. IX(1973), p. 127-172; t. $X(1974)$, p. 155-169).

Otro hispanista francés ha defendido en Burdeos hace un año una espléndida tesis de doctorado titulada Livre et lecture à Valence, 2 vol., 919 p. El período estudiado abarca nada menos que un siglo, desde las aparición de la imprenta (1474-1572), y los distintos planteamientos que se hacen son los siguientes: en la primera parte, la fabricación del libro, los impresores, su condición y su oficio; los editores desde el momento de la elección del texto hasta el de su reproducción, su comercialización, con un excelente estudio cualitativo y cuantitativo. En la segunda parte: la circulación del libro, los libreros, su vida material, sus azares, el léxico y la tipologia de la librería, la evolución de la coyuntura socio-económica y política, y además un buen panorama de la vida literaria, de su devenir, la gran cuestión del retroceso del valenciano como lengua literaria, los niveles de cultura en la ciudad, los inventarios de bibliotecas, y, por fin, un cuantioso indice documental. Todos los archivos asequibles han sido incansablemente consultados por Philippe Berger para la elaboración de esta gran obra, $y$, esencialmente, un $30 \%$ de los protocolos conservados en el Archivo del Reino, en el del Patriarca y en otros fondos. Ningún estudio hasta el presente ha abarcado tan compleja problemática socio-cultural para tan dilatado período. Y conste que la tarea era tanto más ambiciosa 
cuanto que Valencia, en el siglo XVI, fue-como queda ampliamente comprobado-una de las ciudades más cultas de la Cristiandad. Superando por su impresionante documentación los mejores estudios que sobre historia del libro y de la lectura se han Ilevado a cabo, ha revelado Berger, gracias a la paciente consulta y explotación de millares de protocolos, 10 que con dicha fuente es posible rescatar de la vida cultural de una comunidad en épocas remotas. No existe en Francia para una ciudad de provincia un estudio tan global y metódico. El resultado es pues admirable y ejemplar el método. Sólo hace falta que el autor, haciendo de vez en cuando las comparaciones posibles, que por cierto no escasean, dé más perspectiva y ponga más de relieve lo que eran entonces en Europa las realidades editoriales, en relación con las económicas y sociales.

Como logre C. Péligry la oportunidad por él tan deseada de proseguir sus investigaciones sobre la imprenta y la librería del Madrid de los Habsburgos, no cabe duda de que él también realizará una monumental y ejemplar labor, aunque tenga que limitarse a la historia del libro y dejar que otros historiadores emprendan la de los niveles de cultura, de la lectura y de la alfabetización.

Sobre el siglo XVIII puede afirmarse que casi todo queda por hacer. Existen instrumentos de trabajo de gran calidad, como la Historia de los catálogos de libreria españoles (1661-1840). Estudio bibliográfico de A. Rodríguez-Moñino (Madrid, 1966); artículos ya clásicos sobre la exportación de libros a España (gran cuestión ésta, insoslayable) como los de P.-J. Guinard: "Le livre dans la Péninsule ibérique au XVII1 siècle. Témoignage d'un libraire français", Bulletin Hispanique, LIX, 2, Avril-Juin 1957, p. $176-$ 198; G. Bonnat: "La librairie genevoise dans la Péninsule ibérique au XVIII siècle", Genava, nouvelle série, t. III, 1961-1962. p. 103-124. Algunas noticias se encontrarán también, aunque con distintos enfoques, en el libro de M. Defourneaux, L'Inquisition espagnole et les livres français au XVIII ${ }^{\circ}$ siècle, Paris, P.U.F., 1963 y en una sustancial monografía de G. Barber: "The Cramers of Geneva and their trade in Europe between 1775 and 1776", Studies on Voltaire and the XVII/th Century, t. XXX, Genève, 1964, p. 377 413. También hay que tener presentes los repertorios bibliográficos dedicados a unos grandes impresores del Siglo de las Luces, Sancha, Ibarra, Monfort. Además hay en el libro mencionado de A. Rodríguez Moñino numerosas referencias que huelga reproducir aquí. 
Por nuestra parte hemos presentado en un trabajo breve, de próxima aparición, la implantación geográfica y numérica de la librería española a mediados del siglo, explotando una documentación que no tuvo equivalente en ningún período anterior. Seguiremos probablemente explorando este campo hasta poder realizar una sintesis 0 , por lo menos, hasta poder reunir estudios fragmentarios que formen un conjunto coherente dentro de pocos años.

Las cuestiones relativas a la historia del libro y de la lectura durante el muy extenso periodo del Antiguo Régimen han suscitado la organización de un coloquio franco-español en el mes de noviembre de 1980. Catorce ponencias fueron entonces presentadas (siete por franceses, siete por españoles) con gran diversidad de perspectivas y métodos. Como se han impreso los textos leídos, las notas y referencias que los acompañaban y la transcripción de las intervenciones y debates, viene a constituir una aportación esencial Livre et lecture en Espagne et en France sous l'Ancien Régime. Colloque de la Casa de Velázquez, París, Editions A.D.P.F., 1981.

Sobre la primera mitad del siglo XIX, no conocemos otros estudios que los ya indicados por P. Bohigas y A. Rodríguez Moñino. En cambio la segunda mitad de ese siglo ha sido magníficamente estudiada por J.-F. Botrel en su tesis inédita: Pour une histoire littéraire de l'Espagne. 18681914 que, más que de historia del libro, trata constantemente de las principales infraestructuras de la vida cultural en España durante medio siglo. La documentación es abundante, el modo de interrogarla y hacer hablar los hechos es apasionante y muy fecundo. Complementos de esta tesis de título provocante (y peligros, ya que podria inducir a pensar que se trata tan sólo de una de esas adocenadas historias literarias que ignoran a la vez lo histórico y lo literario) son varias monografías elaboradas anteriormente y que enfocan los aspectos más diversos de la vida cultural: el teatro en provincia, la condición material del escritor, la literatura de cordel (en "Les aveugles considérés comme mass media" y en "Aspects de la littérature de colportage en Espagne sous la Restauration").

Los últimos setenta años están sin historiar en la perspectiva que nos interesa, y eso a pesar de que han constituido un periodo de formidable mutación para la edición española. La obra que más roza este tema es la 
de J.-C. Mainer, La Edad de plata (1902-1939), Madrid, Ediciones Cátedra, 1981. Luego la revista El Libro español, publicada por el I.N.L.E. es una fuente constante de informaciones para los que quieran ser historiadores del pasado reciente o del presente.

Pero en nuestra opinión, y no es que queramos sentar cátedra, lo que necesita España es una buena revista de historia del libro, como las que existen en otros países. Las charlas de bibliófilos en algunas trastiendas o algún café, los boletines de escasa difusión, las reproducciones facsimilares de pliegos rarísimos, son cosas entrañables, que incluso se echan de menos en otros paises. Pero ¿no podrian compaginarse con un gran impulso, metódico y sostenido, dado por fin a la bibliografía y a la historia del libro?

\section{NOTAS:}

(1) I. R. Darnton. L'aventure de l'Encyclopédie. 1775-1800. Un best seller au siècle des Lumières. Préface d'Emmanuel Le Roy Ladurie. Paris, Librairie Perrin, 1982, p. 22.

(1 bis) Muy conocidos de los bibliotecarios y estudiosos son los monumentos bibliográficos de ALLISON, A. and GOLDSMITH, V. F. y el Eighteenth Century British Books, que describen toda la producción tipográfica conservada de Inglaterra para los siglos XVI y XVII, y de Gran Bretaña para el XVIII.

(2) Revue française d'histoire du livre, Bordeaux, nouvelle série, 1971, p. 77-108.

(3) Revista de Archivos, Bibliotecas y Museos, 3. época, t. 3 (1899), p. 662-671; t. 4 (1900), p. 267-272; 667-678 y 736-739.

(4) Revue française d'histoire du livre, Bordeaux, nouvelle série, 1977 (n. ${ }^{\circ}$ 16), p. 3-23. 